\title{
EL LIBERALISMO
}

\author{
Roberto Breña \\ El Colegio de México
}

$\mathrm{A}_{\text {tendencia en América Latina a simplificar el liberalismo }}^{\text {pesar de que desde hace varias décadas ha existido una }}$ y a casi homologarlo con cierto liberalismo básicamente estadounidense de corte economicista y conservador, en el ámbito historiográfico occidental contemporáneo está bien establecida la riqueza, diversidad y complejidad doctrinal, ideológica, política y social de esta doctrina, tradición de pensamiento, corriente política, ideología y conjunto de arreglos institucionales, todo a un tiempo. Para dar una visión general de la cobertura que ha recibido el liberalismo en Historia Mexicana desde su fundación, hace 70 años, me pareció indispensable enfocarme en los artículos que centraban su atención explícitamente en el liberalismo o en algún aspecto del mismo. Dicho de otro modo, muchos de los cientos de artículos publicados durante ese lapso en la revista tocan a la tradición liberal, pero de un modo que se puede considerar en cierta medida tangencial o, por lo menos, el liberalismo no es el tema central o más importante. Por tanto, en la revisión que hago aquí sólo he considerado aquellos que se ocupan explícitamente del liberalismo o de alguna de las múltiples facetas del mismo. De no haber fijado estos 
límites (u otros similares), la cantidad de textos a considerar hubiera prácticamente imposibilitado la redacción de una nota hemerográfica como la que me solicitó Historia Mexicana. Va por delante entonces que no están presentes todas las autoras y todos los autores que de una u otra manera se han ocupado del liberalismo en las páginas de la revista.

Las líneas que siguen toman en cuenta 30 artículos que fueron publicados en Historia Mexicana durante sus siete décadas de existencia (el primero es de 1953 y el último de 2020). ${ }^{1}$ Como resulta lógico tratándose de una publicación periódica que se ocupa de historia de México, salvo contadas excepciones el liberalismo que es motivo de estudio es el mexicano; dichas excepciones son los liberalismos español, europeo y argentino. Como cabía esperar también, el autor que más atención ha recibido desde el mirador liberal a lo largo de esos setenta años es José María Luis Mora. Sin embargo, lo que quizá no resulte tan "esperable" es la notable atención concedida al liberalismo durante el porfiriato, una época que en el imaginario popular mexicano está lejos del liberalismo, cuando no en sus antípodas, pero que, por distintos motivos, la historiografía mexicana y mexicanista considera parte integral de nuestra historia liberal.

En relación con la cronología histórica, el siglo xvin y el periodo de la independencia han recibido escasísima atención. Esto es explicable respecto al siglo xviII, en la medida en que en esa

${ }^{1}$ Agradezco a mi colega Alfredo Ávila por sus comentarios y a mi exalumno Rogelio Alcántara por su ayuda para ubicar algunos de los 30 artículos. La lista completa aparece al final de esta nota. Conviene advertir que algunos de los textos revisados (casi todos ellos publicados durante los primeros lustros de Historia Mexicana) son conferencias, ponencias o discursos, los cuales en un par de ocasiones carecen de citas y de bibliografía. Uno de ellos, el de Arnáiz y Freg, es el prólogo de una antología sobre Mora publicada por la UNAM muchos años antes de que el texto apareciera en la revista. Por último, vale la pena precisar que, independientemente de su extensión, en esta nota no consideré las numerosas reseñas dedicadas en la revista a libros que, durante las siete décadas mencionadas, se han ocupado directa o indirectamente del liberalismo. 
centuria el vocablo "liberalismo" no existía con una connotación política. De hecho, el único artículo sobre el tema dedicado a esa centuria habla de "protoliberalismo", un término que conlleva múltiples problemas historiográficos (como, en mi opinión, todos los "protos"). Es menos explicable que el liberalismo del periodo independentista haya sido tratado poquísimo en Historia Mexicana, aunque es cierto que el vocablo "liberalismo" con una significación política surge en Cádiz a fines de la primera década del siglo xix y que "liberalismo hispánico" es una expresión relativamente nueva en la historiografía occidental y, además, muy poco conocida fuera de los ámbitos académicos español y latinoamericano. La falta de atención al estudio del liberalismo durante la independencia novohispana seguramente se modificará en los años por venir, pues el estudio de este periodo desde la perspectiva de la historia política, social e intelectual está haciendo aportaciones importantes desde hace varios lustros y hay señales que permiten pensar que esta tendencia se mantendrá.

Como ya adelanté, el siglo XIX mexicano ha recibido mucha atención desde la perspectiva del liberalismo, algo que no puede sorprender a nadie. Además de lo ya dicho sobre el porfiriato, conviene apuntar que en las páginas de la revista el periodo que va de la obtención de la independencia a la Reforma ha recibido más atención que cualquier otro, aunque obviamente el interés prestado a la Reforma y a la República Restaurada también es considerable. Por su parte, con contadas excepciones, la Revolución ha estado ausente de Historia Mexicana desde una perspectiva liberal explícita. Por último, a juzgar por la ausencia de artículos sobre el liberalismo como objeto de estudio, se puede decir que la tradición liberal desaparece prácticamente de la revista en lo que concierne al resto del siglo xx. Al respecto, se podría decir que los tiempos políticos de la larga hegemonía del partido oficial no se prestaban mucho al estudio del liberalismo.

El penúltimo punto se puede considerar algo que cabía esperar, pues tradicionalmente la Revolución ha sido vista desde 
una perspectiva historiográfica en la que el liberalismo no es la ideología predominante. Si el liberalismo era revolucionario a principios del xIX y, por lo tanto, en el carácter liberal de la independencia reside buena parte de su naturaleza revolucionaria, éste no podía ser el caso 100 años después. Lo anterior no niega que la Constitución de 1917 sea un documento liberal en muchos aspectos y que los arreglos institucionales surgidos de la Revolución no hayan sido liberales, pero hasta la fecha los que se consideran los más grandes logros de la Revolución se ubican dentro de un espectro ideológico que va más allá del liberalismo. Un espectro que cabe definir como radical, progresista, socialista o de izquierda. En cuanto a la ausencia de artículos dedicados al liberalismo durante el periodo posrevolucionario y el resto del siglo XX, el PNR/PRM/PRI nunca fue un partido identificado explícitamente con el liberalismo; salvo, parcialmente, con Jesús Reyes Heroles al frente del CEN, y cuando se intentó hacer una recuperación (fallida) del "liberalismo social" al final de la década de 1980. La ausencia mencionada se explica no sólo por los tiempos en los que surgió el PNR y por la ya referida hegemonía posterior, sino también por otro punto ya mencionado: en la medida en que el partido en el poder se identificara con la Revolución, difícilmente podía también identificarse en la misma medida con el liberalismo. Por lo demás, a partir del inicio de la Guerra Fría, identificarse con el liberalismo implicaba inevitablemente hacerlo en cierta medida con Estados Unidos.

En cuanto a los temas y abordajes historiográficos, sin pretender fijar compartimentos estancos y hasta donde puedo ubicar los distintos y cada vez más porosos campos de la historia, la mayoría de los textos considerados son de historia política. Sin embargo, algunos de ellos pueden ubicarse también sin mayor problema dentro de lo que actualmente se denomina "historia intelectual” (hasta hace poco más conocida como "historia de las ideas"), cuatro se pueden considerar de historia social (incluyo aquí las historias regional y local), dos pueden incluirse dentro 
de la historia eclesiástica, dos corresponden a la historia de la educación, hay dos textos sobre el liberalismo literario (por denominarlo de algún modo), uno de historia agraria, uno de historia militar y, por último, uno pertenece a lo que puede llamarse historia fiscal.

Antes de pasar a ciertas consideraciones generales extraídas de los textos revisados y sin sacar conclusión alguna sobre la temporalidad, indico enseguida la distribución cronológica de los mismos: ocho se ubican en la década de 1950, dos en la de 1960, tres en la de 1970, cinco en la de 1980, tres en la de 1990, cuatro en la primera década del siglo xxi y cinco en la segunda. Por último, quizá convenga apuntar que entre los autores de los 30 textos revisados se encuentran historiadores "clásicos" de la historiografía mexicana y mexicanista, como José Miranda, Leopoldo Zea, Luis González, Moisés González Navarro, Nicole Giron y Charles Hale. Cabe también mencionar aquí a historiadoras e historiadores que siguen en activo y que cuentan con una amplia trayectoria y con una gran reputación académica; entre ellos, Alan Knight, Marcello Carmagnani, Dorothy Tanck, Romana Falcón y Brian Connaughton.

En lo que sigue, haré algunos comentarios generales que surgen de la lectura de los 30 textos considerados para la redacción de esta nota hemerográfica. Esto no quiere decir que todos pesen en la misma medida. No sólo porque la calidad es desigual, como en cualquier otra revista, sino también porque inevitablemente enfatizo los ámbitos historiográficos que conozco mejor $y$, por último, porque no todos los textos "se prestan" en la misma medida, por decirlo así, a algunas de las generalizaciones que haré en los párrafos que siguen. En todo caso, prácticamente no haré una glosa o crítica concreta de ninguno de los textos considerado individualmente, pues no es ése el objeto de estas líneas. Lo que haré son consideraciones generales que, desde mi punto de vista, es posible extraer del conjunto de los artículos. Asimismo, plantearé líneas de reflexión y de discusión que me 
parecen sugerentes sobre la idea que tenemos actualmente del liberalismo mexicano, tanto en el campo académico como en el ámbito público.

Una de las primeras conclusiones que es posible extraer de la lectura de los textos incluidos en esta revisión es la presencia o continuidad del liberalismo mexicano a lo largo del siglo XIX y principios del xx, incluida la Revolución. Respecto a esta última inclusión, para González Navarro la Constitución de 1917 representa el triunfo del liberalismo social y para Knight la revolución mexicana fue un movimiento con un claro predominio ideológico liberal. Con reservas y con matices, pero Knight es uno más de los defensores de la tesis de la continuidad del liberalismo mexicano a lo largo del siglo xix, incluyendo a la Revolución. Sobre este tema, cabe apuntar que, en su artículo sobre el tema, Quirk difiere por completo de esta inclusión, pues para este autor el Congreso de Querétaro significó un triunfo de los radicales; al respecto, Quirk concluye que en dicho congreso los liberales "perdieron la batalla ideológica”. Volviendo a la tesis de la continuidad liberal, tanto para Hale como para Carmagnani existe también una continuidad entre la Reforma y el porfiriato. Esta aparente omnipresencia del liberalismo en la historia de México tiene que ver con un punto que señalé al inicio de estas líneas: la enorme diversidad y amplitud del liberalismo en la historia de Occidente. Al respecto y limitándome al ámbito mexicano (que, insisto, es prácticamente el único bajo estudio en la revista), baste señalar que en los artículos revisados se hace alusión directa o indirecta a los avatares o adjetivos del liberalismo que enumero enseguida: capitalista, moderado, puro, educativo, comercial, libresco, agrario, republicano, democrático, patriótico, conservador, individualista, social, tradicionalista, constitucional, positivista, institucional, triunfante, desarrollista, popular, fiscal, cultural y pragmático.

Con una versatilidad de la magnitud que se desprende del listado anterior, ya no resulta tan difícil entender que el liberalismo 
sea omnipresente en la historia mexicana cuando, en términos reales, el único periodo de la historia nacional durante el cual parece haber prevalecido en términos institucionales fue la década corta conocida como la "República Restaurada”. Subrayo la palabra "parece" porque tres de los artículos incluidos en esta revisión, el de Scholes, el de Ballard y el de Falcón, muestran de manera convincente que en aspectos muy importantes la República Restaurada dista de haber sido un régimen liberal. A este respecto, cabe recordar lo dicho por Charles Hale en el sentido de que la divergencia entre las formas institucionales liberales y la práctica política es la "marca de fábrica” de la historia política latinoamericana (y, por tanto, mexicana, que era la que Hale mejor conocía). Es en parte la magnitud de esta divergencia la que explica que el liberalismo pueda recorrer toda la historia de México sin aparente solución de continuidad y explica también que muchos historiadores (entre ellos varios autores de textos aquí considerados) hablen enfáticamente de la "continuidad" del liberalismo mexicano. Como quedó dicho, para Hale esta continuidad incluye a la Revolución, lo cual nos vuelve a un punto ya mencionado (los contenidos liberales de la Revolución). Este punto suscita, a mi parecer, cuestiones que vale la pena poner sobre la mesa.

Si el liberalismo mexicano empieza con la Constitución de Apatzingán, si la Constitución de 1824 es liberal, si Mora es el gran autor liberal de las primeras décadas de vida independiente, si más adelante vienen la Reforma, Juárez, el liberalismo triunfante y la República Restaurada, si el porfiriato tiene tantos aspectos liberales como algunos historiadores han planteado y si, por último, la revolución de 1910 es un movimiento eminentemente liberal, resulta que la historia mexicana de todo el siglo xIx e incluso la Revolución están bañadas de liberalismo. Esto sólo se puede explicar si volvemos a los muchos y muy variados liberalismos que se desprenden del listado proporcionado líneas atrás. Con una somera revisión del mismo, es claro que 
el liberalismo es ubicuo en nuestra historia no sólo porque las instituciones que surgen del periodo independentista son liberales en términos formales, sino también porque durante todo el siglo XIX hubo pensadores, periodistas y escritores liberales, y también porque incluso dentro de un régimen que en términos reales era más una dictadura que otra cosa (el de Porfirio Díaz), podían darse y desarrollarse un liberalismo literario, un liberalismo educativo y un liberalismo económico. No sólo eso, dentro del amplísimo espectro liberal nos podemos mover hacia la izquierda y nos encontramos entonces bajo el manto del liberalismo social, pero podemos movernos en sentido contrario sin temor a salirnos del paraguas liberal, pues nos encontraríamos al amparo del liberalismo conservador. Esta labilidad que el liberalismo ha manifestado desde sus orígenes es uno de los motivos que explican por qué esta tradición de pensamiento y tradición política se ha mantenido como la ideología predominante hasta nuestros días en el mundo occidental y, se podría decir en la actualidad, en el mundo entero. Para evitar malas interpretaciones, cabe señalar que este predominio presupone esa diversidad doctrinal, ideológica, histórica e institucional del liberalismo a la que me he referido y en la que considero que es importante seguir insistiendo, tanto desde una perspectiva política como historiográfica.

Volviendo a México, la diversidad o pluralidad o incluso indeterminación del liberalismo se manifiesta no solamente respecto a la historia política del liberalismo mexicano, sino también respecto a los autores considerados en varios de los textos revisados para escribir esta nota. Desde el conservadurismo y el pragmatismo de Mora que destacan Florstedt y Rojas, respectivamente, hasta Payno, ese liberal "en tono menor" que tan bien retrata Giron en el artículo que le dedica, pasando por ese supuesto archiconservador que es Alamán, que tan liberal resulta en diversos aspectos desde la perspectiva de Hale, y pasando también por Agustín Rivera, ese eclesiástico cuyos escritos recorren toda la 
segunda mitad del siglo xIX y a quien, a pesar de lo que plantea el autor del artículo sobre este religioso, David Carbajal López, yo no denominaría “teólogo del liberalismo”, como hace Carbajal en el título de dicho artículo. Aunque sólo fuera por la distancia irreconciliable que existió en México (y en prácticamente todo Occidente) entre la Iglesia y el liberalismo, desde los tiempos de Mora y Gómez Farías hasta la Revolución.

Otra manera en que el carácter proteico del liberalismo decimonónico se manifiesta es un hecho ya mencionado. Empezando por el único texto que se ocupa de algunas facetas liberales del ideario insurgente, el de Breña, hasta el liberalismo ideológico y sociopolítico de la revolución mexicana que destaca Knight, de uno u otro modo el liberalismo recorre la posindependencia, las convulsas décadas de 1830 y 1840, la guerra con Estados Unidos (que tan de cerca siguiera Mora desde la distancia), la Reforma por supuesto, la guerra entre liberales y conservadores, el imperio de Maximiliano (para González Navarro, varias de las políticas de Maximiliano son un ejemplo de liberalismo social), la República Restaurada por supuesto, el porfiriato y, por último, la Revolución. Solo una ideología proteica puede ser supuestamente ubicua a lo largo de toda una centuria con constituciones, publicistas, escritores, políticos, emperadores, dictadores, pronunciamientos, guerras, planes, insurrecciones, regímenes, levantamientos, administraciones y gobiernos tan disímiles como los que recorren el siglo XIX mexicano.

Si la Revolución reforzó el mito liberal, como plantea Hale en el segundo de los dos textos de este autor revisados aquí, se podría hablar sin mayores prevenciones de una ubicuidad del liberalismo en la historia de México. Desde mi punto de vista y como expresé en otro lugar, las preocupaciones sociales, los objetivos políticos, los contextos de debate, el tipo de sociedad que se pretendía edificar, las prioridades institucionales y las acciones estatales se modificaron tanto a lo largo de la centuria que va de 1820 a 1920 que insistir en la continuidad 
del liberalismo me parece una opción interpretativa que, si bien tiene diversos argumentos atendibles a su favor, invita a adentrarnos en una noche en la que todos los gatos son pardos y obstaculiza identificar las peculiaridades de cada uno de los distintos momentos que recorren la historia decimonónica mexicana. ${ }^{2}$ Creo que afirmar categóricamente, como hace Hale, que durante el porfiriato los debates políticos se dieron dentro de una "institución liberal", que las ideas liberales eran "parte integral de la política mexicana” y que el pensamiento político de la época puede definirse como un "liberalismo triunfante" suscita tantas dudas como certezas.

El punto anterior me lleva al tema con el que cerraré estas líneas: la cuestión del "fracaso" del liberalismo mexicano. La cual, me parece, contribuye a explicar la supuesta omnipresencia del liberalismo en nuestra historia. Entrecomillo la palabra fracaso porque es claro que en la historia incluso de los fracasos más sonados surgen aspectos que matizan el uso del término. Incluso se podría debatir si esta palabra no debe ser eliminada de la historia o, más bien, de la historiografía. Dicho esto, basta leer con mediana atención algunos de los 30 textos considerados aquí para que proceda decir algo sobre dicho vocablo, que tanto disgusta a ciertos historiadores mexicanos.

Para no extenderme mucho y en el orden en que aparecieron en la revista, me remito enseguida a algunos de esos 30 artículos. Para Scholes, la República Restaurada cargó el acento sobre el orden y dejó la libertad para más tarde. Para Arnáiz y Freg, desde 1833 la vida de Mora tiene mucho de "cosa malograda", nada menos. González concluye su artículo hablando sobre la "derrota" del agrarismo reformista. Para Miranda, los liberales

2 "La magna obra de Charles Hale", reseña del libro El pensamiento político en México y Latinoamérica (Artículos y escritos breves) de Charles A. HALE, Josefina Z. VÁzquez y Gabriel Torres Puga (eds.), Estudios de historia moderna y contemporánea de México, 43 (ene.-jun. 2012), pp. 178-188: http:// www.revistas.unam.mx/index.php/ehm/article/view/32071/29540 
mexicanos y españoles fracasaron en casi todo, empezando por la desamortización y siguiendo con el ámbito estrictamente político, en el que predominaron la "democracia de fachada", los "tinglados electorales" y los "cuartelazos, pronunciamientos, motines e intrigas". En opinión de Powell, la Reforma "fue un periodo trágico para el campesinado indígena de México". Ballard, por su parte, considera que el liberalismo teórico de los hombres de la Reforma, la Constitución de 1857 y la República Restaurada fue "refutado" por las realidades sociales y políticas del país. Carmagnani considera que el federalismo fiscal porfirista fracasó por motivos eminentemente políticos. Para Falcón, algunas de las represiones de levantamientos campesinos e indígenas que llevó a cabo el aparato estatal de la República Restaurada son equiparables a los infaustos sucesos que tuvieron lugar en Cananea y Río Blanco durante el porfiriato, nada menos. Para Breña, la insurgencia novohispana era profundamente tradicionalista en aspectos muy importantes, por lo que deberíamos ser escépticos respecto al supuestamente acendrado liberalismo insurgente que cierta historiografía nacionalista ha planteado (y sigue planteando). Por último, para Rangel Silva, el supuesto orden liberal de la última etapa del porfiriato era en realidad "una máscara de la legalidad y la modernidad".

Como resulta evidente, si por un lado podemos hablar de la presencia, omnipresencia, continuidad o ubicuidad del liberalismo en la historia de México (por la menos hasta la Revolución e incluyéndola), con la misma autoridad o legitimidad historiográfica podemos hablar de las deficiencias, limitaciones, lagunas o vacíos de esta tradición política (en la historia de México o en cualquier otra, por si hiciera falta aclararlo). Los artículos que he leído para redactar esta nota han dado y siguen dando argumentos, casi en la misma medida, para ambas opciones interpretativas. En otras palabras, la discusión historiográfica sobre la continuidad o discontinuidad del liberalismo mexicano y sobre su naturaleza real o imaginaria, efectiva o epidérmica, sigue con 
nosotros. En consonancia con lo expresado en esta nota, cabe inferir que este debate no tiene "solución", no tiene "salida", y, en consecuencia, seguirá acompañando a la historiografía mexicana.

Lo anterior es una muestra más de esa labilidad y complejidad del liberalismo a las que me he referido aquí y en otros textos que he escrito sobre el tema. Esta cuestión me parece crucial, so pena de aceptar acríticamente ciertas visiones angostas, muchas veces ahistóricas y casi siempre interesadas que simplifican sobremanera una tradición política de enorme riqueza. Una riqueza que, sin embargo, no debe ser obstáculo para calibrar y sopesar, mucho menos negar, el carácter ideológico que es consustancial al liberalismo.

Dicha riqueza es la fuente de la vitalidad política, social, cultural e intelectual que ha mostrado el liberalismo desde hace más de 200 años en la historia de Occidente y en buena parte de la historia decimonónica de México. Una vitalidad que, por cierto, está siendo puesta a prueba en el momento actual, tanto en Occidente como en nuestro país, en donde un liberalismo que proclamó prematuramente su victoria y que ha estado de capa caída desde hace alrededor de dos décadas está buscando a tientas nuevos referentes, nuevos anclajes y nuevas perspectivas. Por motivos eminentemente políticos, a últimas fechas el liberalismo mexicano ha tenido que reinventarse y reapuntalarse. Los resultados de este proceso de reajuste y el posible surgimiento de un liberalismo renovado o distinto son cuestiones que se manifestarán, tanto en la academia como en la vida pública, en los años por venir.

ARTÍCULOS REVISADOS

(EN ORDEN CRONOLÓGICO)

1. Scholes, Walter V., "El liberalismo reformista” (7), 1953, pp. 343-352.

2. Quirk, Robert E., "Liberales y radicales en la Revolución Mexicana” (8), 1953, pp. 503-528. 
3. ZEA, Leopoldo, "Hacia un nuevo liberalismo en la educación” (20), 1956, pp. 528-548.

4. Arnaiz y Freg, Arturo, "El doctor Mora, teórico de la reforma liberal” (20), 1956, pp. 549-571.

5. Miranda, José, "El liberalismo español hasta mediados del siglo XIX” (22), 1956, pp. 161-199.

6. Reyes de la Maza, Luis, "Nicolás Pizarro, novelista y pensador liberal” (24), 1957, pp. 572-587.

7. GonzÁlez y GonzÁlez, Luis, "El agrarismo liberal” (28), 1958, pp. 469-496.

8. Miranda, José, "El liberalismo mexicano y el liberalismo europeo" (32), 1959, pp. 512-523.

9. Hale, Charles A., "Alamán, Antuñano y la continuidad del liberalismo" (42), 1961, pp. 224-245.

10. Florstedt, Robert F., "Mora y la génesis del liberalismo burgués” (42), 1961, pp. 207-223.

11. Powell, T. G., "Los liberales, el campesinado indígena y los problemas agrarios durante la Reforma" (64), 1972, pp. 653-676.

12. Ballard, Laurens Perry, "El modelo liberal y la política práctica en la República Restaurada” (92), 1974, pp. 646699.

13. Quintero, Adelina, "La trayectoria política de Rafael Odriozola, primer liberal oaxaqueño" (193), 1977, pp. 456-481.

14. González Navarro, Moisés, “Tipología del liberalismo mexicano" (126), 1982, pp. 198-225.

15. Tanck de Estrada, Dorothy, "Ilustración y liberalismo en el programa de educación primaria de Valentín Gómez Farías" (132), 1984, pp. 463-508.

16. KNight, Alan, "El liberalismo mexicano desde la Reforma hasta la Revolución (Una interpretación)” (137), 1985, pp. 59-91. 
17. TAYlor, Lawrence Douglas, "Voluntarios extranjeros en los ejércitos liberales mexicanos, 1854-1867” (146), 1987, pp. 205-237.

18. Carmagnani, Marcello, "El liberalismo, los impuestos internos y el Estado federal mexicano, 1857-1911” (151), 1989, pp. 471-496.

19. Pietschmann, Horst, "Consideraciones en torno al protoliberalismo, reformas borbónicas y revolución. La Nueva España en el último tercio del siglo xviII" (162), 1991, pp. 167-205.

20. Giron, Nicole, "Manuel Payno, un liberal en tono menor” (173), 1994, pp. 5-35.

21. Hale, Charles A., "Los mitos políticos de la nación mexicana, el liberalismo y la Revolución” (184), 1997, pp. 821837.

22. Rangel Silva, José Alfredo, "Lo que antes era casa de Dios... adaptaciones del liberalismo en los ámbitos locales, 1820-1825” (209), 2003, pp. 117-177.

23. Forte, Riccardo, "Los acuerdos de Ayutla (1854) y de San Nicolás (1852) y las constituciones liberales. Orígenes del poder coactivo del Estado en México y Argentina” (212), 2004, pp. 863-910.

24. FAlcón, Romana, "El Estado liberal ante las rebeliones populares. México, 1867-1876” (216), 2005, pp. 973-1048.

25. Connaughton, Brian, “¿Una república católica dividida? La disputa eclesiológica heredada y el liberalismo ascendente en la independencia de México” (236), 2010, pp. 1141-1204.

26. Rojas, Rafael, "Mora en París (1834-1850). Un liberal en el exilio, un diplomático ante la guerra” (245), 2012, pp. 7-57.

27. Rangel Silva, José Alfredo, "Los comuneros, el abogado y el senador, cultura política y orden liberal a fines del Porfiriato” (255), 2015, pp. 937-1000. 
28. BREÑA, Roberto, "La España peninsular y la Nueva España ante los acontecimientos de 1808. El liberalismo gaditano y la insurgencia novohispana en una era revolucionaria" (261), 2016, pp. 161-208.

29. Pérez Montesinos, Fernando, "Geografía, política y economía del reparto liberal en la meseta purépecha, 18511914" (264), 2017, pp. 2073-2149.

30. Carbajal, David, "Agustín Rivera, teólogo del liberalismo; sermones y discursos de un clérigo y escritor público, 1854-1916” (276), 2020, pp. 1549-1596. 
